\title{
Electrochemical and Photoelectrochemical Behaviors of Polythiophene Nanowires Prepared by Templated Electrodeposition in Supercritical Fluids Ken SAKAMOTO, ${ }^{a}$ Koji NAKABAYASHI, ${ }^{a}$ Toshio FUCHIGAMI, ${ }^{a}$ and Mahito ATOBE ${ }^{a}, b, *$
}

\author{
a Department of Electronic Chemistry, Tokyo Institute of Technology, \\ 4259 Nagatsuta-cho, Midori-ku, Yokohama 226-8502, Japan \\ b Department of Environment and System Sciences, Yokohama National University, \\ 79-7 Tokiwadai, Hodogaya-ku, Yokohama 240-8501, Japan
}

* Corresponding author: atobe@ynu.ac.jp

\begin{abstract}
The electrochemical and photoelectrochemical behaviors of polythiophene nanowires prepared by templated electrodeposition in supercritical fluids were investigated. The polythiophene nanowires prepared showed sharp and strong capacitive redox waves in its cyclic voltammogram and excellent photocurrent responsivity in its cyclic voltammogram under photo-irradiation. These were better results compared to those obtained by the use of polythiophene films deposited on the flat disc electrode. This is mainly due to the fact that surface area of nanowires are much larger than that of flat films.
\end{abstract}

(C) The Electrochemical Society of Japan, All rights reserved.

Keywords : Nanowire, Templated Electropolymerization, Supercritical Fluid, Polythiophene

\section{Introduction}

Recently, considerable attention has been directed toward the fabrication of one-dimensional nanoscale materials because they exhibit novel physical properties, which differ from those of bulk materials, and have potentialities for a broad range of applications in electron field emitter, biosensor, optical filter, and so on. ${ }^{1-4}$ Templated synthesis is an elegant chemical approach for the fabrication of nanowires. Especially, the templated electrodeposition has been proved to be effective way to fabricate metal, its alloy, and conducting polymer nanowires. ${ }^{5-9}$ This method entails the electrochemical synthesis of a desired material within pores of a nanoporous membrane. However, the nanostructure fabrication of these materials by using nanoporous templates, particularly by using the templates with high aspect ratio conduits, was carried out with great difficulty due to poor substrate transfer typically associated with liquid-phase electrodeposition. Hence, the nanostructure fabrication using templated electrodeposition has still remained a challenging target.

Because supercritical fluids exhibit larger diffusivility and lower viscosity compared to those of conventional liquids, ${ }^{10-13}$ we envisioned that the use of supercritical fluids as electrolytic media for templated electrochemical deposition would enable the effective precursor transport into pores of template membrane and the nanoprecise filling with the materials. In fact, we preliminary reported that this concept worked successfully in the templated electrochemical deposition of polythiophene (PTh) in a supercritical fluid such as $\mathrm{scCHF}_{3}{ }^{14,15}$ Furthermore, uniform and well-aligned PTh nanowire arrays could be obtained by dissolving a template membrane.

On the other hand, it is well known that PTh and its derivatives behave similarly to p-type semiconductors, ${ }^{16}$ and therefore they have been used in polymeric solar cells. ${ }^{17}$ In recent studies, the oneand two-dimensional periodic nanostructure of p-type semiconducting polymers are considered to be ideal for high-efficiency polymeric solar cells since the efficient photo-induced charge separation should be occurred at their quite large interface. ${ }^{17,18}$ Hence, uniform and well-aligned PTh nanowire arrays prepared by our synthetic method would be also good candidate materials for high-efficiency polymeric solar cells. With these in mind, in this primitive study, not only the electrochemical but also the photoelectrochemical behavior of PTh nanowire arrays prepared by templated electrodeposition in $\mathrm{scCHF}_{3}$ were investigated.

\section{Experimental}

The synthesis of PTh nanowire arrays using templated electrodeposition in $\mathrm{scCHF}_{3}$ was reported in detail elsewhere. ${ }^{14,15}$ Nanoporous alumina membranes $(60 \mu \mathrm{m}$ thick, $200 \mathrm{~nm}$ pore size, $13 \mathrm{~mm}$ diameter, Anodisc 13, Whatman) coated on one side with evaporated $\mathrm{Au}$ (ca. $100 \mathrm{~nm}$ thick) were employed as templates for PTh electrodeposition into pores. In a stainless steel cell $\left(96 \mathrm{~cm}^{3}\right.$ volume, Taiatsu Techno, Co.) equipped with working electrode (templated $\mathrm{Au}$ electrode), counter electrode (Pt plate, $2 \times 2 \mathrm{~cm}^{2}$ ), quasi reference electrode (Ag wire), and sapphire window for the observation of the cell inside, thiophene monomer $(10 \mathrm{mM})$ and $\mathrm{TBABF}_{4}(100 \mathrm{mM})$ as a supporting electrolyte were added, then liquid $\mathrm{CHF}_{3}$ was injected at $15 \mathrm{MPa}$ from a LC pump (NP-D-321J, Nihon Seimitsu Kagaku Co.) connected to a $\mathrm{CHF}_{3}$ gas cylinder. The cell was heated to $50^{\circ} \mathrm{C}$ to create a supercritical state. The electrochemical polymerization of thiophene was carried out by a constant potential method $(2.4 \mathrm{~V}$ vs. Ag wire). After the electropolymerization, the alumina template was removed in $4.0 \mathrm{M} \mathrm{NaOH}$, and the sample was rinsed in $\mathrm{H}_{2} \mathrm{O}$ and dried under reduced pressure. Finally the sample was subjected to scanning electron microscopy (SEM, VE-8800, KEYENCE Co.) and electrochemical measurements. For comparison, the electropolymerization was carried out using a conventional $\mathrm{Au}$ disc electrode $(1.0 \mathrm{~cm}$ diameter) under the same electrolytic conditions in $\mathrm{scCHF}_{3}$, and the obtained PTh film sample was also subjected to SEM and electrochemical measurements.

Cyclic voltammetry of PTh nanowire arrays and PTh films was performed by using a computer-controlled electrochemical analyzer (ALS/CH Instruments $630 \mathrm{C}$ ). The voltammograms were recorded in $100 \mathrm{mM} \mathrm{TBABF} 4$ acetonitrile solution after the solution was deaerated by bubbling $\mathrm{N}_{2}$ gas for $20 \mathrm{~min}$. Pt plate $\left(2 \times 2 \mathrm{~cm}^{2}\right)$ and 

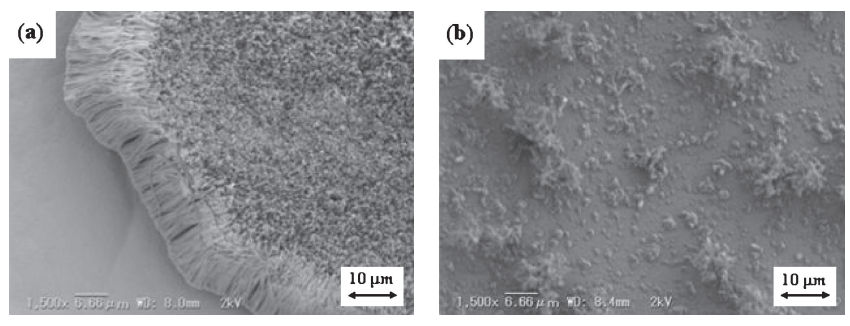

Figure 1. SEM images of PTh samples subjected to electrochemical measurements. (a) PTh nanowires and (b) PTh film. Both samples were prepared in $\mathrm{scCHF}_{3}$ at $2.4 \mathrm{~V}$ vs. $\mathrm{Ag}$ wire by passing $1.28 \mathrm{C} \mathrm{cm}^{-2}$ of electricity.

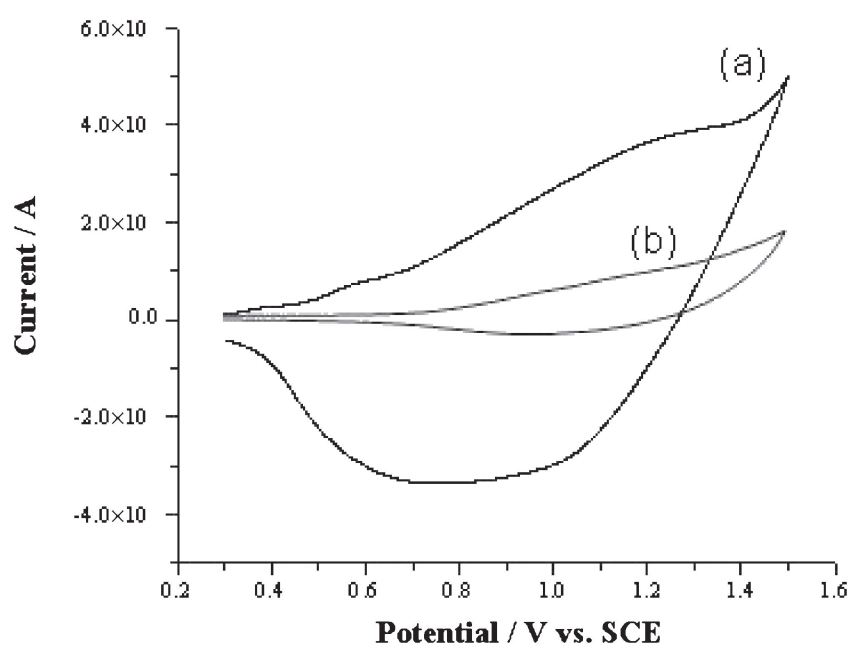

Figure 2. Cyclic voltammograms of (a) PTh nanowires and (b) $\mathrm{PTh}$ film modified $\mathrm{Au}$ electrodes. Both samples were prepared in $\mathrm{scCHF}_{3}$ at $2.4 \mathrm{~V}$ vs. $\mathrm{Ag}$ wire by passing $1.28 \mathrm{C} \mathrm{cm}^{-2}$ of electricity. Scan rate was $50 \mathrm{mV} \mathrm{s}^{-1}$.

saturated calomel electrode (SCE) were used as counter and reference electrodes, respectively.

The photoelectrochemical measurements were caried out in $100 \mathrm{mM} \mathrm{TBABF}_{4}$ acetonitrile solution containing the saturated molecular oxygen as an electron scavenger. An $\mathrm{Hg}$-Xe lamp (Sanei Electric Co. Supercure-205S, $1.5 \mathrm{~W} \mathrm{~cm}^{-2}$ at $365 \mathrm{~nm}$ ) was used as a light source. The lamp irradiates spectral lines in the range of ca. 300 to $450 \mathrm{~nm}$.

\section{Results and Discussion}

Figure 1 shows SEM images of PTh samples subjected to electrochemical measurements. It could be confirmed that the PTh nanowires and PTh film were obtained by the electrochemical polymerization in $\mathrm{scCHF}_{3}$ using a templated $\mathrm{Au}$ electrode and conventional $\mathrm{Au}$ disc electrode, respectively.

Figure 2 shows cyclic voltammograms of PTh nanowires and $\mathrm{PTh}$ film modified Au electrodes prepared in $\mathrm{scCHF}_{3}$. Both samples were prepared by passing the same electricity $\left(1.28 \mathrm{C} \mathrm{cm}^{-2}\right)$ and gave a typically reversible redox response associated with the doping and dedoping processes. ${ }^{19}$ However, the magnitude of the redox current peaks of the nanowire sample is significantly bigger than that of the film one. This can be ascribed to large surface area of the PTh nanowire sample, that is, the PTh wires synthesized by the templated electropolymerization in $\mathrm{scCHF}_{3}$ were highly aligned without falling down, and hence the effective surface area for the doping and dedoping processes should be significantly larger compared to that of the PTh film prepared using a Au disc electrode.

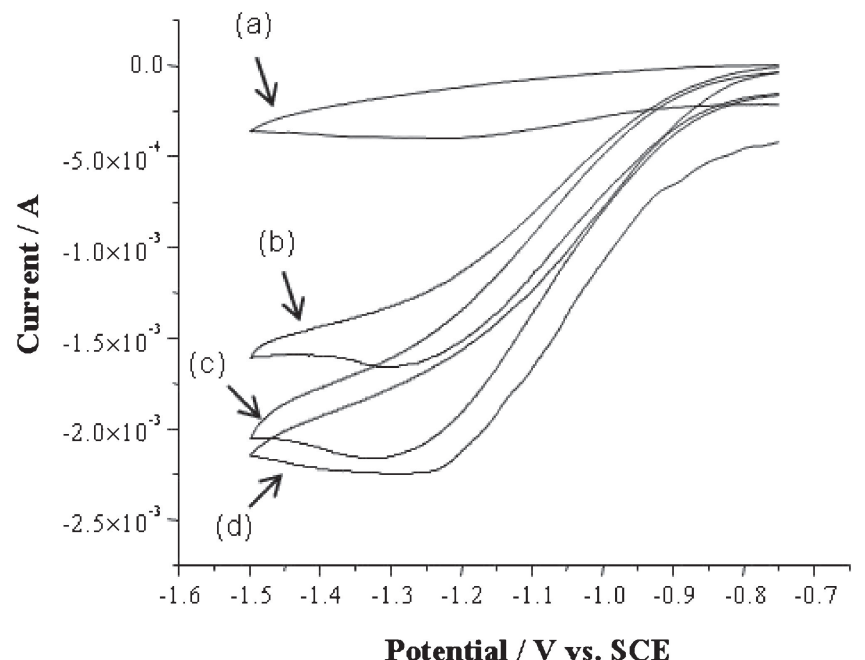

Figure 3. Cyclic voltammograms of (a) PTh film and (b-d) PTh nanowires. PTh film was prepared in $\mathrm{scCHF}_{3}$ at $2.4 \mathrm{~V}$ vs. Ag wire by passing $1.92 \mathrm{C} \mathrm{cm}^{-2}$ of electricity. PTh nanowires were prepared in $\mathrm{scCHF}_{3}$ at $2.4 \mathrm{~V}$ vs. Ag wire by passing (b) $1.28 \mathrm{C} \mathrm{cm}^{-2}$ (average nanowire length, $6 \mu \mathrm{m}$ ), (c) $1.92 \mathrm{C} \mathrm{cm}^{-2}$ (average nanowire length, $9 \mu \mathrm{m}$ ), and (d) $3.85 \mathrm{C} \mathrm{cm}^{-2}$ (average nanowire length, $18 \mu \mathrm{m}$ ) of electricity. The voltammograms were recorded at $20 \mathrm{mV} \mathrm{s}^{-1}$ of scan rate in $100 \mathrm{mM} \mathrm{TBABF} 4$ acetonitrile solution containing the saturated molecular oxygen as an electron scavenger under the light irradiation by an $\mathrm{Hg}$-Xe lamp.

Photoreductive currents were observed in the reductive cyclic voltammetry in the presence of the saturated molecular oxygen (electron scavenger) when PTh nanowires modified Au electrodes were irradiated by an Hg-Xe lamp (Fig. 3). In sharp contrast, the photoreductive current was hardly observed in the PTh film case. In these measurements, PTh samples were irradiated through an Au substrate electrode (ca. $100 \mathrm{~nm}$ thick) by the Hg-Xe lamp. Therefore, in the PTh film case, it can be expected that the irradiated light did not reached to an interface between the film and electrolyte because of the densely packed sample structure. On the other hand, probably the light could reach effectively to the interface due to porous sample structure in the PTh nanowire case. In addition, it was also found that the current was increased with an increasing the wire length of the sample, and almost saturated at $9 \mu \mathrm{m}$ in average wire length. This means that $9 \mu \mathrm{m}$ wire length is enough to absorb light irradiated from the lamp.

Figure 4 shows photoreductive current of PTh nanowires in response to turn-on and turn-off the photoirradiation. The photocurrent exponentially increased within about $5 \mathrm{~s}$ and then gradually saturated in the turn-on state. After the photoirradiation was turn-off, the current decreased within about $10 \mathrm{~s}$. Four cycles of photocurrent switching clearly demonstrated the response reproducibility of the PTh nanowires. Although a clear photocurrent response was hardly observed with the PTh film sample in this work, Semenikhin and coworkers reported photocurrent of the electropolymerized PTh fim. ${ }^{16}$ However, the magnitude of photocurrent reported was much lower and its response against on/off switching photoirradiation was apparently slower than that observed in Fig. 4. The possible reasons are attributed to that the PTh nanowires have larger interfacial area and shorter transmission length compared to the PTh films. Thus, the nanowires made by the small radius exhibits higher photocurrent and shorter response time.

\section{Conclusions}

The electrochemical as well as photoelectrochemical behaviors of $\mathrm{PTh}$ nanowires prepared by templated electrodeposition in $\mathrm{scCHF}_{3}$ 


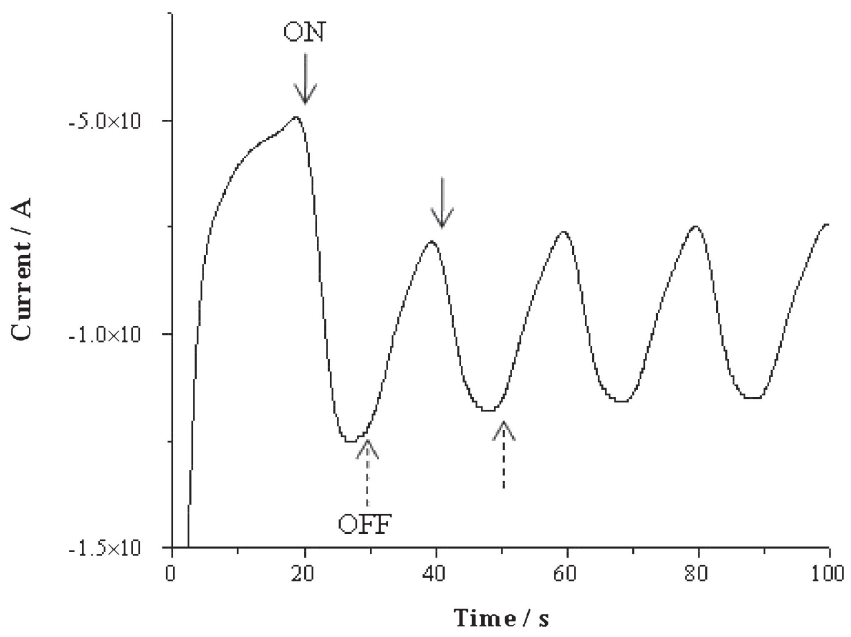

Figure 4. Photoreductive current of PTh nanowires in response to turn-on and turn-off the photoirradiation. The sample was prepared in $\mathrm{scCHF}_{3}$ at $2.4 \mathrm{~V}$ vs. $\mathrm{Ag}$ wire by passing $1.92 \mathrm{C} \mathrm{cm}^{-2}$ of electricity.

were studied, and compared to those of PTh films electrodeposited on the flat disc electrode. The PTh nanowires show better perfomance (electrochemical and photoelectrochemical responses) than the PTh films. The possible reasons are attributed to that the PTh nanowires have larger interfacial area and shorter transmission length compared to the PTh films. Therefore, we believe that the PTh nanowires hold great promise for use in high-efficiency polymeric solar cells. Consequently, the application to the polymeric solar cells is in progress.

\section{Acknowledgments}

This work was supported by the Grants-in-Aid for Scientific Research (20350046, 21656205, and 22106508) from the Japanese Ministry of Education, Culture, Sports, Science and Technology.

\section{References}

1. J. Hu, T. W. Odom, and C. M. Lieber, Acc. Chem. Res., 32, 435 (1999).

2. Z. L. Wang, Adv. Mater., 12, 1295 (2000)

3. Y. Xia, P. Yang, Y. Sun, Y. Wu, B. Mayers, B. Gates, Y. Yin, F. Kin, and H. Yan, Adv. Mater., 15, 353 (2003).

4. X. Lu, W. Zhang, C. Wang, T.-C. Wen, and Y. Wei, Prog. Polym. Sci., 36, 671 (2011).

5. R. P. Burford and T. Tongtam, J. Mater. Sci., 26, 3264 (1991).

6. C. A. Foss, G. L. Hornyak, J. A. Stockert, and C. R. Martin, Adv. Mater, 5, 135 (1993).

7. C. B. Gorman, H. A. Biebuyck, and G. M. Whitesides, Chem. Mater, 7, 526 (1995).

8. B. B. Lakshmi, C. J. Patrissi, and C. R. Martin, Chem. Mater, 9, 2544 (1997).

9. T. Kyotani, B. K. Pradhan, and A. Tomita, Bull. Chem. Soc. Jpn., 72, 1957 (1999).

10. A. O'Neil and J. J. Watkins, MRS Bull., 30, 967 (2005).

11. J. M. Blackburn, D. P. Long, A. Carbanas, and J. J. Watkins, Science, 294, 141 (2001).

12. A. I. Cooper, Adv. Mater, 15, 1049 (2003).

13. R. Noyori, Chem. Commun., 13, 1807 (2005).

14. M. Atobe, S. Iizuka, T. Fuchigami, and H. Yamamoto, Chem. Lett., 36, 1448 (2007).

15. M. Atobe, N. Yoshida, K. Sakamoto, K. Sugino, and T. Fuchigami, Electrochim. Acta, 87, 409 (2013).

16. O. A. Semenikhin, E. V. Ovsyannikova, N. M. Alpatova, Z. A. Rotenberg, and V. E. Kazarinov, J. Electroanal. Chem., 463, 190 (1999).

17. G. Dennler, M. C. Scharber, and C. J. Brabec, Adv. Mater., 21, 1323 (2009).

18. J. R. Tumbleston, D.-H. Ko, E. T. Samulski, and R. Lopez, Appl. Phys. Lett., 94, 043305 (2009).

19. X. Li, M. Lu, and H. Li, J. Appl. Polym. Sci., 86, 2403 (2002). 